\title{
Article \\ Effects of Intercooling Intensity on Temperature Field and Microstructure of Large-Scale 2219 Al Alloy Billet Prepared by Internal Electromagnetic Stirring Casting
}

\author{
Yang Qiu ${ }^{1,2, *}$, Xintao Li ${ }^{1,2}$, Mingyang Liu ${ }^{1,2}$, Nan Zhou ${ }^{1,2}$ and Kaihong Zheng ${ }^{1,2}$ \\ 1 Institute of New Materials, Guangdong Academy of Sciences, Guangzhou 510630, China; \\ lxt_hq@163.com (X.L.); liumingyang4671@163.com (M.L.); zhounan@gdinm.com (N.Z.); \\ zhkaihong2003@163.com (K.Z.) \\ 2 Guangdong Provincial Key Laboratory of Metal Toughening Technology and Application, \\ Guangzhou 510630, China \\ * Correspondence: qiuyang@gdinm.com
}

\section{check for}

updates

Citation: Qiu, Y.; Li, X.; Liu, M.;

Zhou, N.; Zheng, K. Effects of

Intercooling Intensity on

Temperature Field and

Microstructure of Large-Scale 2219 Al

Alloy Billet Prepared by Internal

Electromagnetic Stirring Casting.

Materials 2022, 15, 1809. https://

doi.org/10.3390/ma15051809

Academic Editor: Francesco

Iacoviello

Received: 31 January 2022

Accepted: 22 February 2022

Published: 28 February 2022

Publisher's Note: MDPI stays neutral with regard to jurisdictional claims in published maps and institutional affiliations.

Copyright: (C) 2022 by the authors. Licensee MDPI, Basel, Switzerland. This article is an open access article distributed under the terms and conditions of the Creative Commons Attribution (CC BY) license (https:// creativecommons.org/licenses/by/ $4.0 /)$.

\begin{abstract}
Internal electromagnetic stirring is an advanced melt treatment method, which can be used in direct chill casting to prepare large-scale $\mathrm{Al}$ alloy billets. Intercooling intensity is a primary parameter of internal electromagnetic stirring; its effects on temperature fields and microstructures have been investigated via numerical simulations and industrial experiments, respectively. The simulated results show an increase in the intercooling affected area and a decrease in sump depth with an increase in the intercooling heat transfer coefficient. The heat transfer coefficient should not exceed $500 \mathrm{~W} /\left(\mathrm{m}^{2}{ }^{\circ} \mathrm{C}\right)$ because the solid fraction of the intercooling end bottom may exceed $50 \%$. The experiment's results demonstrate that the average grain sizes in the edge, $1 / 2$ radius, and center are $151 \pm 13 \mu \mathrm{m}, 159 \pm 14 \mu \mathrm{m}$, and $149 \pm 16 \mu \mathrm{m}$, respectively, under a liquid nitrogen flow rate of $160 \mathrm{~L} / \mathrm{min}$, which is much finer than that of $80 \mathrm{~L} / \mathrm{min}$ and more homogeneous than that of $240 \mathrm{~L} / \mathrm{min}$. Furthermore, an experimental liquid nitrogen flow rate of $80 \mathrm{~L} / \mathrm{min}, 160 \mathrm{~L} / \mathrm{min}$, and $240 \mathrm{~L} / \mathrm{min}$ approximately correspond to the simulated heat transfer coefficient of $200 \mathrm{~W} /\left(\mathrm{m}^{2}{ }^{\circ} \mathrm{C}\right)$, $300 \mathrm{~W} /\left(\mathrm{m}^{2}{ }^{\circ} \mathrm{C}\right)$, and $400 \mathrm{~W} /\left(\mathrm{m}^{2}{ }^{\circ} \mathrm{C}\right)$, respectively.
\end{abstract}

Keywords: large-scale billet; internal electromagnetic stirring; intercooling intensity; temperature field; microstructure

\section{Introduction}

Coarse and inhomogeneous microstructures always occur during conventional direct chill casting (DCC) of billets, an issue that usually worsens as the scale of the billet and range of solidification increases [1-4]. Deformation processes, such as rolling and forging, can refine a microstructure, but cannot significantly improve its inhomogeneity [5]. On the contrary, under certain conditions deformation may actually aggravate the microstructure's inhomogeneity. When the strain temperature is low and the strain rate is high, some defects, such as cracking, flow localization, and an adiabatic shear band may occur, resulting in poor workability of as-cast materials and lower relative mechanical properties in as-deformed materials [6-8]. Hence, it is vital to obtain fine and homogeneous microstructures in billets [9-11].

A large number of studies have shown that the abovementioned problems can be solved by using electromagnetic stirring (EMS) during DCC [12-15]. However, the skin effect applies to conventional EMS, demonstrating that the penetration depth of the magnetic field into the melt is limited [16]. The magnetic induction intensity in the center melt is too small to generate effective electromagnetic stirring effects. Therefore, conventional EMS can only be applied to small-scale billets. To solve this problem, the annular EMS method was proposed; inserting a core into the melt center [17,18]. An annular gap is formed between 
the core and the hot top mold, avoiding the weak stirring area and greatly increasing the shear strength of the electromagnetic force. However, annular EMS does not fundamentally change the traditional heat transfer pattern (from outside to inside); the melt temperature field is always very inhomogeneous, especially in large-scale billets. Therefore, a uniform DCC method, which involves inserting an in-mold cooler (with a cooling function) into the melt center $[19,20]$, is proposed. The cooler occupies the melt center, which reduces the temperature of the center melt to a certain extent while, simultaneously, most of the heat at the liquid sump can be continuously removed by passing a cooling medium into the cooler. In addition, the existence of an annular also accelerates the forced convection generated by the EMS. Based on uniform DCC, the internal EMS (IEMS) method, which integrates EMS and intercooling, was proposed as a more advanced and convenient method [21,22]. Compared to uniform DCC, the stirring pattern is changed from the outside-to-inside of conventional EMS to the inside-to-outside of IEMS. Large-scale 2219, 7050, and $7075 \mathrm{Al}$ alloy billets with fine and inhomogeneous microstructures have been obtained via IEMS DCC (internal electromagnetic stirring direct chill casting) [21-23].

As an Al-Cu-Mn series alloy, the 2219 aluminum alloy has high weldability, fracture toughness, and stress corrosion resistance [24,25]. It also maintains excellent strength and toughness from temperatures as low as $-250{ }^{\circ} \mathrm{C}$ to those as high as $300{ }^{\circ} \mathrm{C}$. Hence, it is widely used in the aerospace industry, especially in the storage tanks of space vehicles [26,27]. In this paper, a $2219 \mathrm{Al}$ alloy billet, with a diameter of $508 \mathrm{~mm}$, was chosen as the researched material. As intercooling intensity is one of the most important parameters for the IEMS DCC process, numerical simulations and industrial experimentations, subject to different intercooling intensities, will be carried out in order to investigate its effects on temperature fields and microstructures.

\section{Materials and Methods}

Figure 1 shows a two-dimensional schematic and a three-dimensional geometric model of the IMES DCC process. To simplify the mathematical model and decrease calculations, the following assumptions were made: (1) the displacement current was ignored; (2) the Joule heat was ignored; (3) the effects of melt velocity changes on electromagnetic field distribution was ignored; (4) the melt is an incompressible fluid; (5) all of the melt is in its homogeneous phase $[28,29]$.

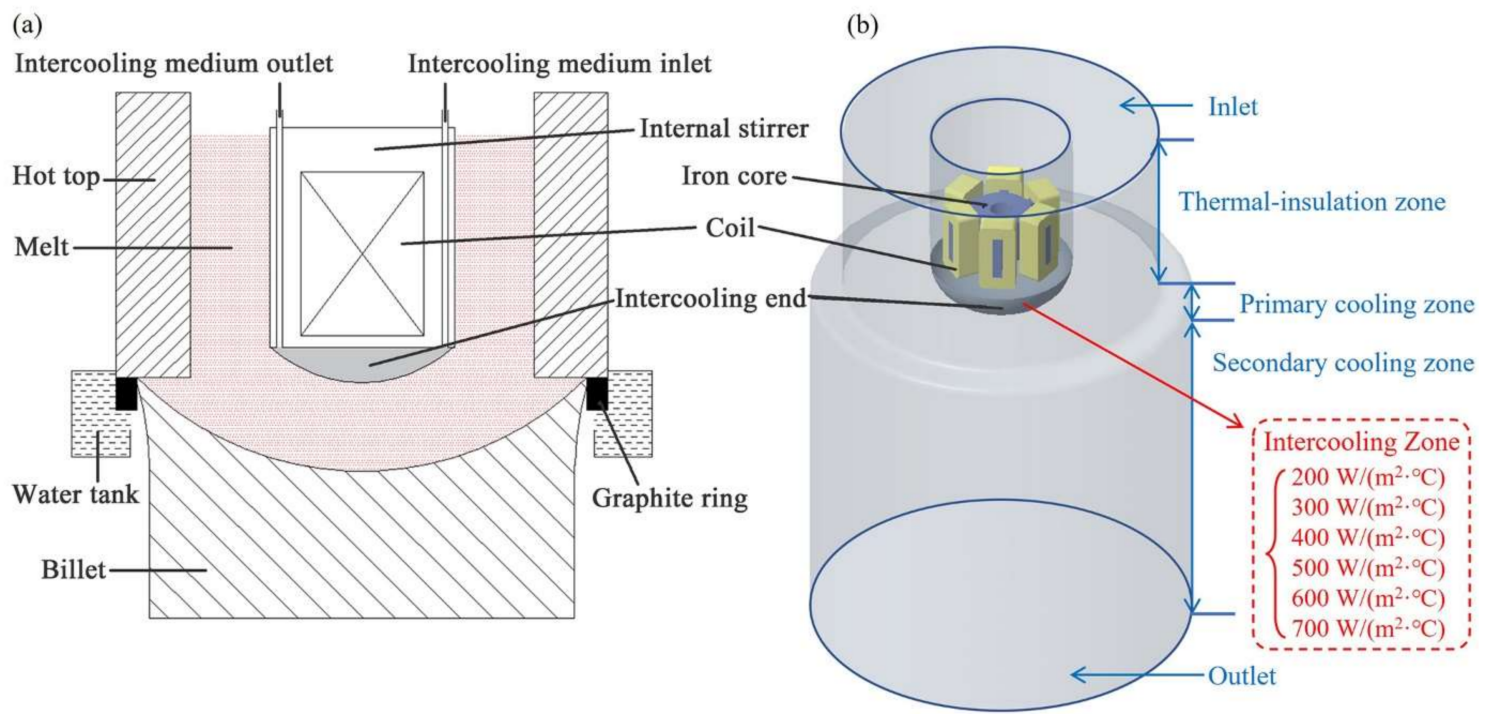

Figure 1. IMES DCC process: (a) two-dimensional schematic; (b) three-dimensional geometry models and boundary conditions. 


\subsection{Governing Equations}

The simulation is coupled with the temperature field (including solidification), flow field, and electromagnetic field. Hence, the following governing equation should be solved:

Continuity equation:

$$
\frac{\partial\left(\rho u_{i}\right)}{\partial x_{i}}=0
$$

Momentum equation:

$$
\rho \frac{\partial u_{i} u_{j}}{\partial x_{j}}=\frac{\partial}{\partial x_{j}}\left[\mu_{e f f}\left(\frac{\partial u_{i}}{\partial x_{j}}+\frac{\partial u_{j}}{\partial x_{i}}\right)\right]-\frac{\partial P}{\partial x_{i}}+\rho g+F+S
$$

in which the $\rho, \mu_{e f f}, P, F, g$, and $S$ are density, the effective viscosity coefficient, pressure, Lorentz force, gravity acceleration, and source term generated by dendrite flowing in the mushy zone, respectively. The $u_{i}$ and $u_{j}$ are velocity components in the $x_{i}$ and $x_{j}$ direction, respectively. The $x_{i}$ and $x_{j}$ are coordinates in the $x_{i}$ and $x_{j}$ direction, respectively.

$$
\begin{gathered}
S=\frac{\left(1-f_{L}\right)^{2}}{\left(f_{L}^{3}+\delta\right)} A_{m u s h}\left(u-u_{S}\right) \\
f_{L}=\left\{\begin{array}{cl}
0 & \left(T \leq T_{S}\right) \\
1-\frac{1}{1-k_{P}} \frac{T_{L}-T}{T_{f}-T} & \left(T_{S}<T<T_{L}\right) \\
1 & \left(T \geq T_{L}\right)
\end{array}\right.
\end{gathered}
$$

in which the $\delta$ is minima (ensuring the denominator is not equal to 0 ); $A_{m u s h}, u_{s}$, and $f_{L}$ are mushy zone constant, casting velocity, and liquid fraction, respectively, and $k_{P}$, $T_{S}, T_{L}$, and $T_{f}$ are solute partition coefficient, solidus, liquidus, and pure metal melting temperature, respectively.

Energy equation:

$$
\begin{gathered}
\frac{\partial}{\partial t}(\rho h)+\nabla \cdot(\rho h u)=\nabla \cdot\left(k_{t} \nabla T\right)+S_{h} \\
h=\int_{298.15 K}^{T} c_{p} d T
\end{gathered}
$$

in which the $h, k_{t}, S_{h}$, and $c_{p}$ are enthalpy, thermal conductivity, solidification latent heat, and specific heat, respectively.

The electromagnetic field governing equations include Maxwell's equations and Ohm's Law:

$$
\begin{gathered}
\nabla \times H=J \\
\nabla \times E=-\frac{\partial B}{\partial t} \\
\nabla \cdot B=0 \\
J=\sigma E
\end{gathered}
$$

in which the $H, J, E, B$, and $\sigma$ are magnetic field intensity, induced current density, electric field intensity, magnetic induction intensity, and electrical conductivity, respectively.

The Lorentz force can be calculated by the following relationship:

$$
F=J \times B
$$

The magnetic field was calculated by Maxwell software (v16, 2012, Ansoft Co., Pittsburgh, PA, USA) and then imported to the Magnetohydrodynamics (MHD) module of ANSYS Workbench Fluent. After having been calculated, the temperature field, includ- 
ing temperature distribution, sump morphology, and depth would be presented in the CFD-Post module of the Workbench.

\subsection{Boundary Conditions}

The boundary conditions were set up approximately, according to the IEMS DCC process. As shown in Figure 1b, the boundary conditions of simulated areas are defined in blue, while the intercooling area is defined in red. The inlet and outlet were set as velocity inlet and velocity outlet. In the hot top area, a thermal-insulation wall was set up. In order to more accurately simulate the process of heat transference, user-defined functions were compiled and applied to the primary and secondary cooling zones.

In the primary cooling zone, solidification shrinkage occurred when the melt made contact with the graphite ring. An air gap occurred, causing a decrease in the heat transfer coefficient. According to the conclusions of Caron's research, and considering the solidus and liquidus of the $2219 \mathrm{Al}$ alloy, the heat transfer coefficient in the primary cooling zone can be expressed by [30]:

$$
h=\left\{\begin{aligned}
1500, & (T>916 K) \\
28.5 T-24,600, & (916 K \geq T \geq 866 K) \\
75, & (T<866 K)
\end{aligned}\right.
$$

In the secondary cooling zone, the heat transfer is very complicated. Forced convection, nucleate boiling, transition boiling, and film boiling may occur, depending on the temperature of the billet's surface. According to the results of Weckman's research, the heat transfer coefficient can be simplified down to the following two conditions [31]:

when nucleate boiling occurs,

$$
h_{b}=(-167,000+704 \bar{T}) Q^{1 / 3}+\frac{20.8 \Delta T_{x}^{3}}{\Delta T}
$$

when forced convection occurs,

$$
h_{c}=(-167,000+704 \bar{T}) Q^{1 / 3}
$$

A criterion can be used to judge whether nucleate boiling occurs:

$$
h_{i}=3910\left(\Delta T_{x}\right)^{2.16}
$$

in which the $\bar{T}$ is the average temperature of cooling water, $Q$ is the flow rate of cooling water in the unit's perimeter, $\Delta T_{x}$ is the difference between billet surface temperature and water saturation temperature, and $\Delta T$ is the difference between billet surface temperature and cooling water temperature.

The heat transfer coefficient in the secondary cooling zone can be expressed by:

$$
h= \begin{cases}h_{c}, & \mid h_{i} \leq h_{c} \\ h_{b}, & \mid h_{i}>h_{c}\end{cases}
$$

In the intercooling zone, intercooling intensity was characterized by the heat transfer coefficient and then acted on the bottom contact area of the intercooler and melt (intercooling end). The intercooling medium and the inner surface of intercooling end contact. Then the heat transfer occurs. The abovementioned heat flux can be approximately equivalent to the melt heat transfer via the intercooling end. Hence, the heat transfer coefficient can be calculated by [32]:

$$
h=\frac{m c\left(t_{1}-t_{2}\right) F_{1}}{\left(t_{3}-t_{4}\right) F_{2}}
$$


in which $m, c, t_{1}, t_{2}$, and $F_{1}$ are mass flux pre-unit area, specific heat capacity, outflow temperature, inflow temperature, and flow channel cross-section area of intercooling medium, respectively, and $t_{3}, t_{4}$, and $F_{2}$ are outer surface temperature, inner surface temperature, and surface area of intercooling end, respectively.

\subsection{Materials and Properties}

The $2219 \mathrm{Al}$ alloy to be used for simulation and experimentation is $\mathrm{Al}-6.35 \mathrm{Cu}-0.32 \mathrm{Mn}$ $0.13 \mathrm{~V}-0.18 \mathrm{Zr}-0.06 \mathrm{Ti}$. 15. Points of different positions were measured to determine its average chemical composition using a direct reading spectrometer (Oxford Instrument Foundry-Master Pro, Oxford, Great Britain). Thermal properties were calculated by JMatPro software (7.0, 2017, Sente Software Ltd., Guildford, Great Britain) and are shown in Figure 2. Meanwhile, its solidification, latent heat, electrical conductivity, and relative magnetic permeability are $385,000 \mathrm{~J} / \mathrm{kg}, 3,800,000 \mathrm{~S} / \mathrm{m}$, and 1, respectively. For the electromagnetic stirrer, the relative magnetic permeability of copper coils and iron cores are 1 and 2000 , respectively.
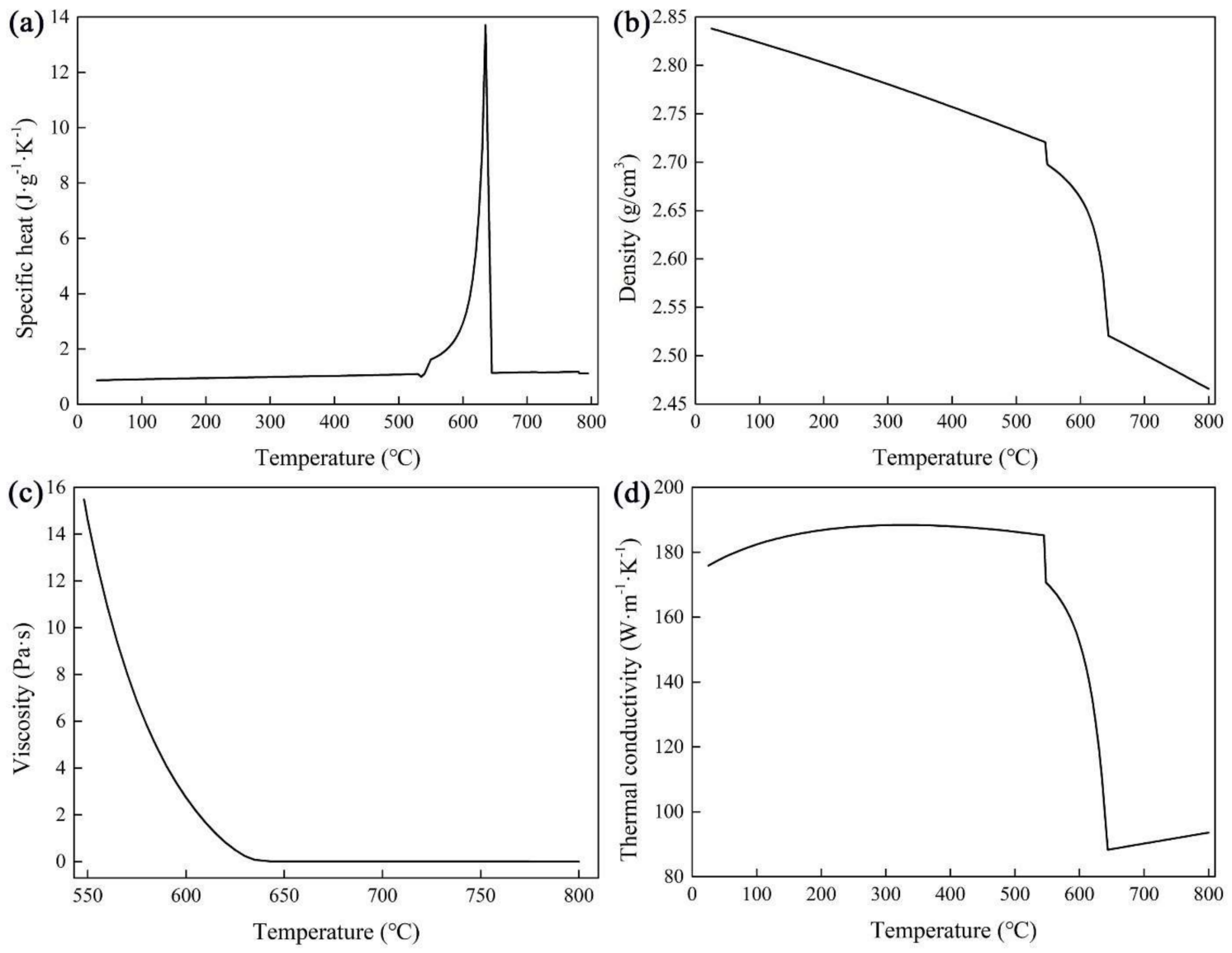

Figure 2. Thermal properties of $\mathrm{Al}-6.35 \mathrm{Cu}-0.32 \mathrm{Mn}-0.13 \mathrm{~V}-0.18 \mathrm{Zr}-0.06 \mathrm{Ti}$ alloy. (a) Specific heat; (b) Density; (c) Viscosity; (d) Thermal conductivity.

\subsection{Experimentation}

The pure industrial $\mathrm{Al}$, pure industrial $\mathrm{Cu}, \mathrm{Al}-10 \mathrm{Mn}, \mathrm{Al}-10 \mathrm{~V}$, and $\mathrm{Al}-10 \mathrm{Zr}$ master alloys were melted in a medium frequency induction furnace and then transferred to a holding furnace. After compositional adjustments, melt purification, and refinement (add Al-5Ti-B), we began stirring in the bottom of the furnace to promote the homogeneous distribution of compositions. When the grain refiner had been completely melted, and the melt temperature had decreased to the casting temperature, DCC began. The melt temperature of the hot top was $650^{\circ} \mathrm{C}$, the casting speed was $0.0004 \mathrm{~m} / \mathrm{s}$, and the second water-cooling rate was $120 \mathrm{~L} / \mathrm{min}$. For the IEMS DCC, the internal stirrer was inserted into 
the hot top center, in which the intercooling end bottom was $10 \mathrm{~mm}$ below the graphite ring top. The alternating current ampere-turns and frequency were $1000 \mathrm{At}$ and $20 \mathrm{~Hz}$, respectively. It should be noted that the side surface of the internal stirrer was covered by thermal insulation material. Hence, no heat transfer occurs in this zone. All of the parameters applied to the simulation are the same as the abovementioned. The differences between the experiment's parameters and those of the simulation are brought about due to the type of intercooling intensity used; the former is a flow rate of intercooling liquid nitrogen $(80-240 \mathrm{~L} / \mathrm{min})$, while the latter is heat transfer coefficient $\left(200-700 \mathrm{~W} /\left(\mathrm{m}{ }^{\circ} \mathrm{C}\right)\right.$ ).

The magnetic induction intensity in the half-height of the coil was tested using a gauss meter. The actual results were compared with the simulated results. Meanwhile, the microstructures undergoing different intercooling intensities were anode coated in a $3 \%$ $\mathrm{HBF}_{4}$ aqueous solution under direct voltage, $30 \mathrm{~V}$ for $20 \mathrm{~s}$, and then observed using a Zeiss Axiovert 200 MAT optical microscope (Carl Zeiss Microscopy GmbH, Jena, Germany). The average grain size was determined using the linear intercept method (ASTM E112-10). The second phases were observed using a ZEISS GeminiSEM 300 (Carl Zeiss Microscopy GmbH, Jena, Germany). The mechanical properties were tested using a SHIMADZU AG-250kN IS tensile machine (SHIMADZU Co., Kyoto, Japan).

\section{Results}

\subsection{Magnetic Induction Intensity}

Figure 3 shows the magnetic induction intensity of different distances from the coil under alternating current ampere-turns 2500 At and frequency $20 \mathrm{~Hz}$, respectively. The actual results and simulated results appear to verify similar trends as the distance from the coil increases. Moreover, the differences between the two are relatively small, which demonstrates the accuracy and credibility of the simulation.

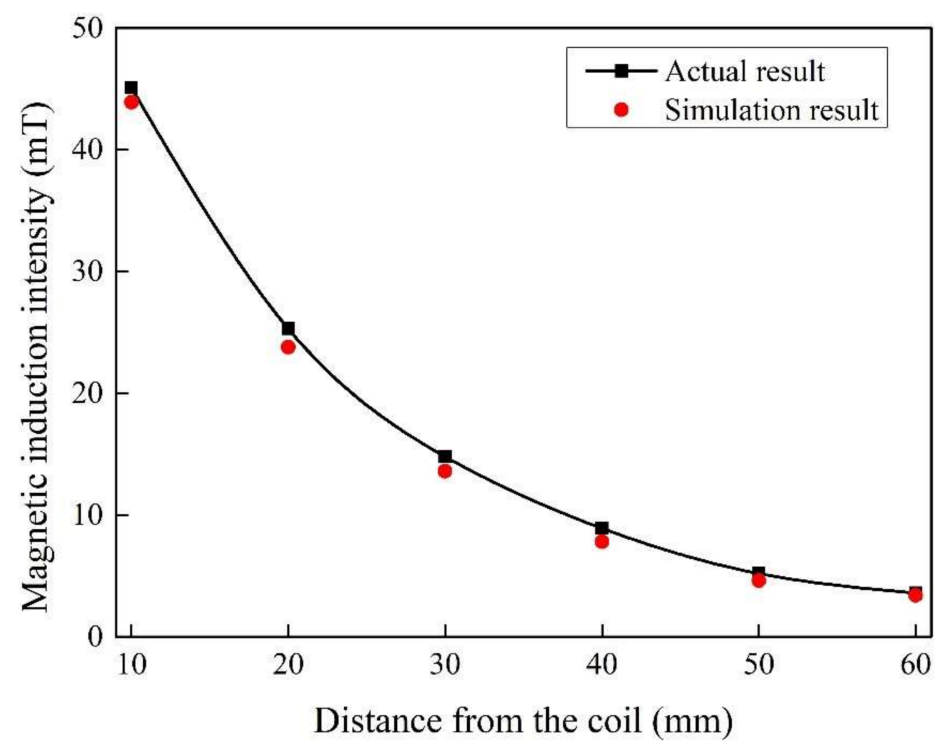

Figure 3. Comparison of the actual and simulated results for magnetic induction intensity.

\subsection{Temperature Field}

Temperature distribution in the longitudinal section of the IEMS DCC billet is shown in Figure 4 . When the intercooling heat transfer coefficient is $200 \mathrm{~W} /\left(\mathrm{m}^{2}{ }^{\circ} \mathrm{C}\right)$, the intercooling effect is weak, and the temperature decreased area is only in the nearby intercooling end. As the intercooling intensity increases, its affected area of increases, and the temperature of the center melt decreases gradually. When the heat transfer coefficient reaches $700 \mathrm{~W} /\left(\mathrm{m}^{2}{ }^{\circ} \mathrm{C}\right)$, the affected distance of intercooling increases significantly in a vertical direction, and the affected radius in the horizontal direction also increases accordingly. 


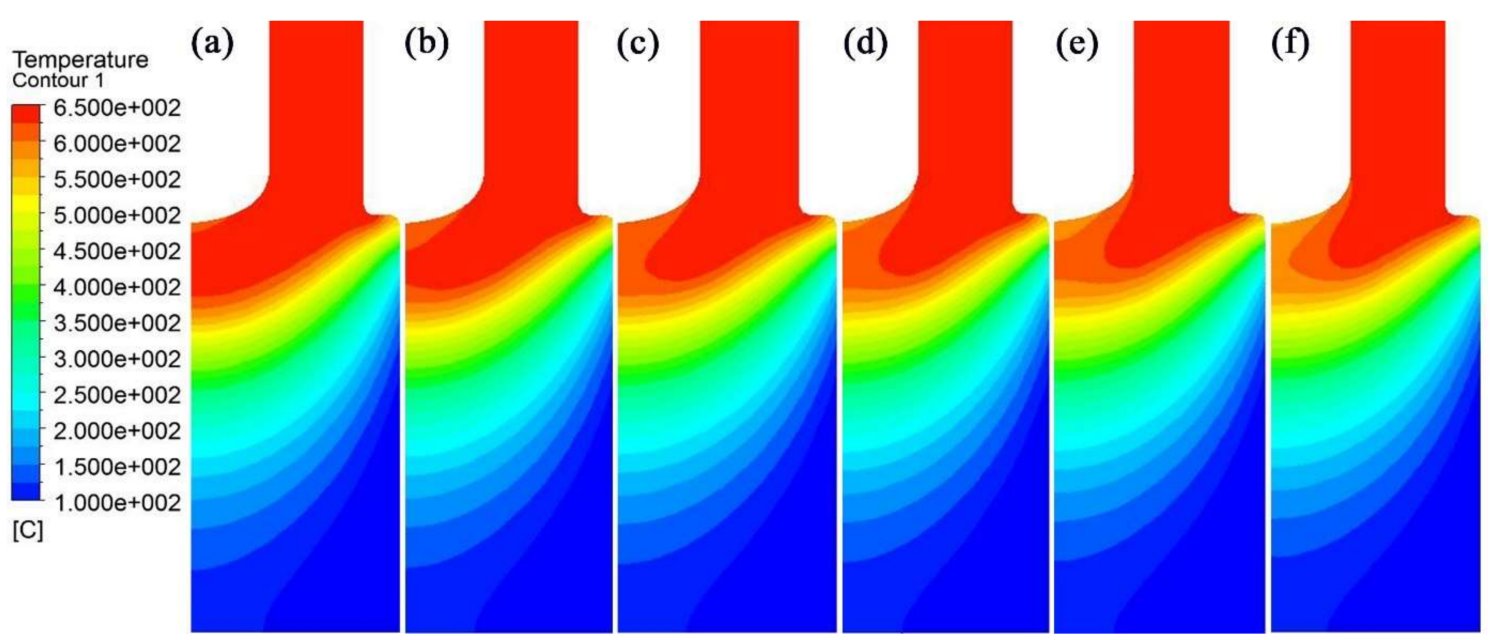

Figure 4. Temperature distribution under different intercooling heat transfer coefficients: (a) $200 \mathrm{~W} /\left(\mathrm{m}^{2}{ }^{\circ} \mathrm{C}\right)$; (b) $300 \mathrm{~W} /\left(\mathrm{m}^{2}{ }^{\circ} \mathrm{C}\right)$; (c) $400 \mathrm{~W} /\left(\mathrm{m}^{2}{ }^{\circ} \mathrm{C}\right)$; (d) $500 \mathrm{~W} /\left(\mathrm{m}^{2}{ }^{\circ} \mathrm{C}\right)$; (e) $600 \mathrm{~W} /\left(\mathrm{m}^{2}{ }^{\circ} \mathrm{C}\right)$; (f) $700 \mathrm{~W} /\left(\mathrm{m}^{2}{ }^{\circ} \mathrm{C}\right)$.

The sump in the longitudinal section of the IEMS DCC billet is shown in Figure 5. With the increase in the intercooling heat transfer coefficient, the sump depth becomes shallower and the morphology becomes much gentler. The sump depth and solid fraction of the intercooling end bottom are measured, respectively, and shown in Figure 6. When the heat transfer coefficient increases from $200 \mathrm{~W} /\left(\mathrm{m}^{2}{ }^{\circ} \mathrm{C}\right)$ to $700 \mathrm{~W} /\left(\mathrm{m}^{2}{ }^{\circ} \mathrm{C}\right)$, the sump depth decreases from $135 \mathrm{~mm}$ to $110 \mathrm{~mm}$, and the solid fraction of the intercooling end bottom increases from $22 \%$ to $66 \%$. When the solid fraction of the intercooling end bottom reaches $50 \%$, the risk of the internal stirrer solidifying into the billet increases. Hence, it is considered that the intercooling heat transfer coefficient should not exceed $500 \mathrm{~W} /\left(\mathrm{m}^{2}{ }^{\circ} \mathrm{C}\right)$, accordingly.

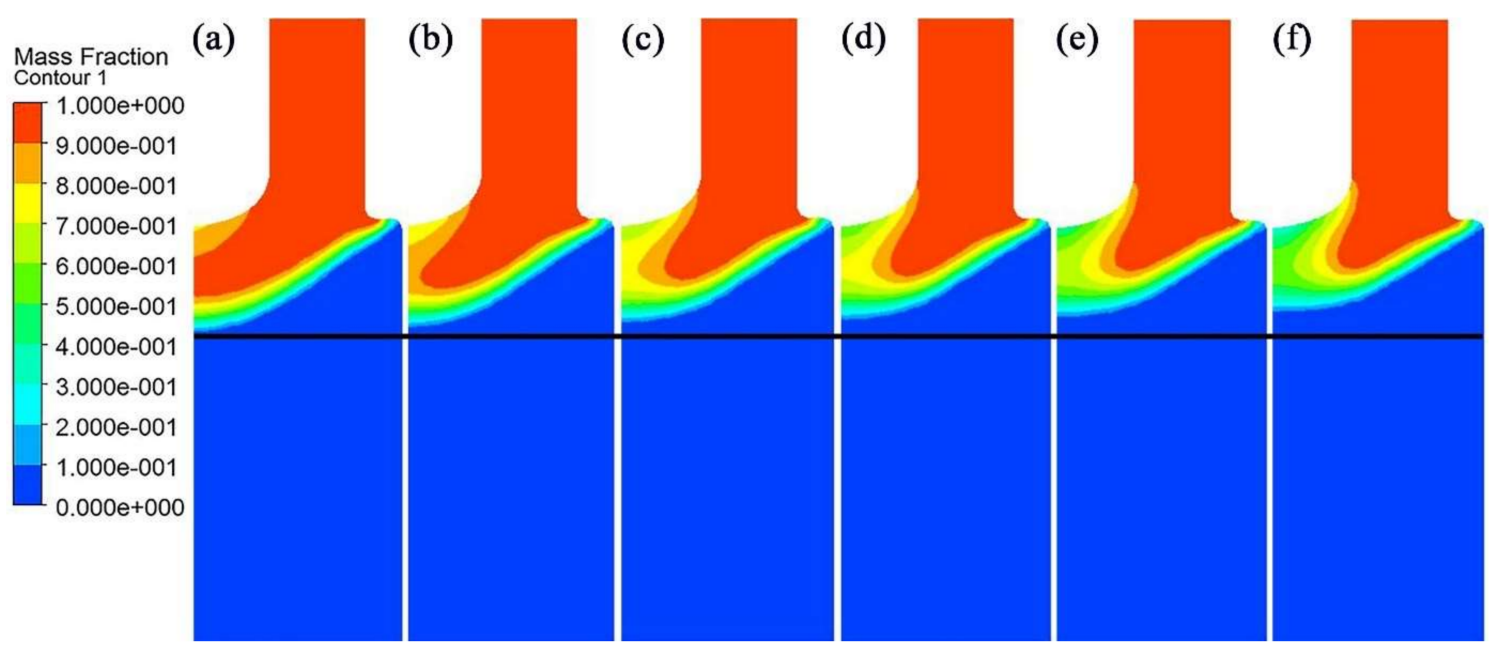

Figure 5. Sump under different intercooling heat transfer coefficients: (a) $200 \mathrm{~W} /\left(\mathrm{m}^{2}{ }^{\circ} \mathrm{C}\right)$; (b) $300 \mathrm{~W} /\left(\mathrm{m}^{2}{ }^{\circ} \mathrm{C}\right) ;\left(\right.$ c) $400 \mathrm{~W} /\left(\mathrm{m}^{2}{ }^{\circ} \mathrm{C}\right)$; (d) $500 \mathrm{~W} /\left(\mathrm{m}^{2}{ }^{\circ} \mathrm{C}\right) ;\left(\right.$ e) $600 \mathrm{~W} /\left(\mathrm{m}^{2}{ }^{\circ} \mathrm{C}\right) ;(\mathbf{f}) 700 \mathrm{~W} /\left(\mathrm{m}^{2}{ }^{\circ} \mathrm{C}\right)$. 
(a)

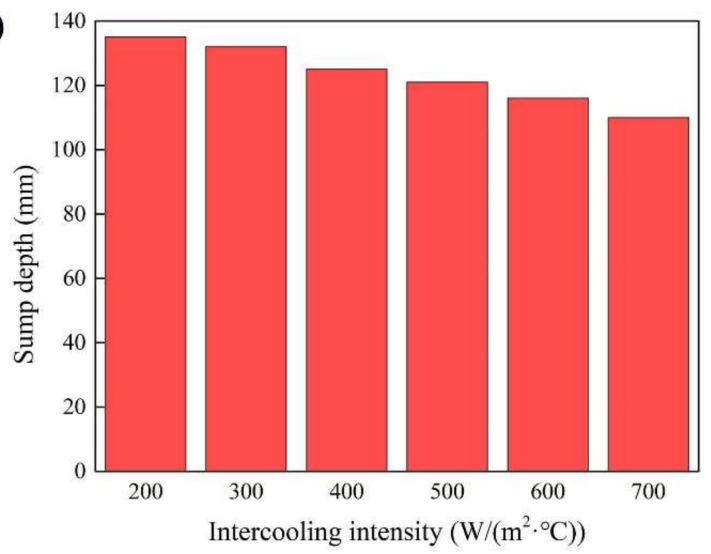

(b)

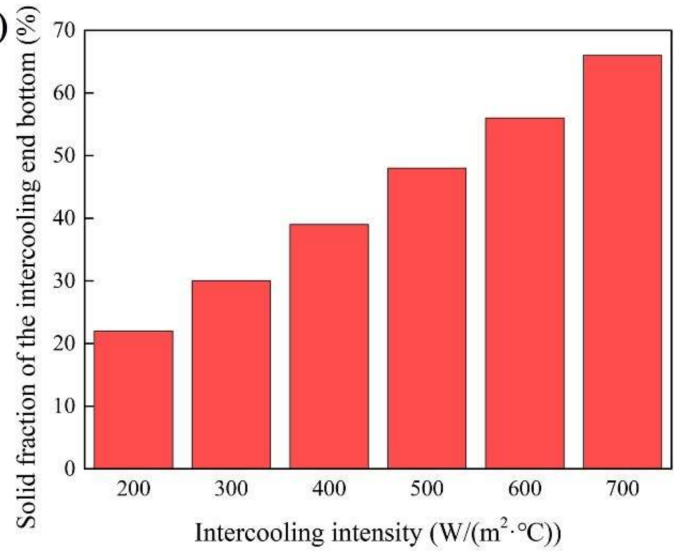

Figure 6. (a) Sump depth and (b) solid fraction of the intercooling end bottom.

\subsection{Microstructure}

Figure 7 shows the microstructure in the edge $(\mathrm{a}, \mathrm{d}, \mathrm{g}), 1 / 2$ radius $(\mathrm{b}, \mathrm{e}, \mathrm{h})$, and center $(\mathrm{c}, \mathrm{f}, \mathrm{i})$ of the billet under a liquid nitrogen flow rate of $80 \mathrm{~L} / \mathrm{min}(\mathrm{a}-\mathrm{c}), 160 \mathrm{~L} / \mathrm{min}(\mathrm{d}-\mathrm{f})$, and $240 \mathrm{~L} / \mathrm{min}(\mathrm{g}-\mathrm{i})$, respectively. When the liquid nitrogen flow rate is $80 \mathrm{~L} / \mathrm{min}$, the microstructure is very coarse; the average grain sizes are $297 \pm 47 \mu \mathrm{m}, 286 \pm 41 \mu \mathrm{m}$, and $317 \pm 56 \mu \mathrm{m}$ in the edge, $1 / 2$ radius, and center, respectively. The microstructure is refined significantly as the liquid nitrogen flow rate increases to $160 \mathrm{~L} / \mathrm{min}$. From edge to center, the average grain sizes decrease to $151 \pm 13 \mu \mathrm{m}, 159 \pm 14 \mu \mathrm{m}$, and $149 \pm 16 \mu \mathrm{m}$, respectively. It should be noted that the homogeneity of the microstructure has also been improved significantly. When the liquid nitrogen flow rate reaches $240 \mathrm{~L} / \mathrm{min}$, the microstructure in the edge maintains the refinement trend, with its average grain size decreasing to $108 \pm 11 \mu \mathrm{m}$. Approaching the center, the microstructure becomes coarse and inhomogeneous, with the average grain sizes of $303 \pm 71 \mu \mathrm{m}$ and $399 \pm 77 \mu \mathrm{m}$ in the $1 / 2$ radius and center, respectively.
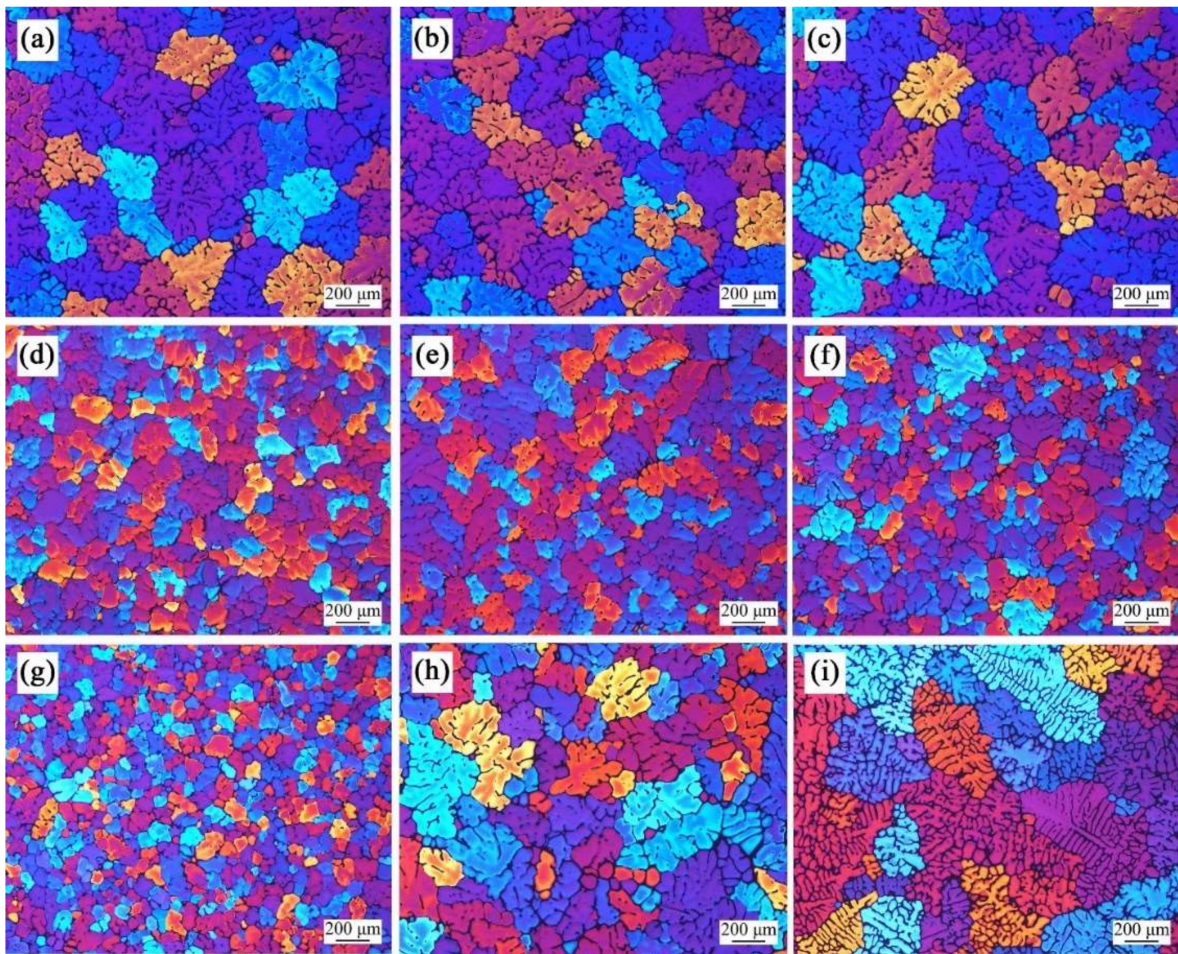

Figure 7. Microstructure in the edge $(\mathbf{a}, \mathbf{d}, \mathbf{g}), 1 / 2$ radius $(\mathbf{b}, \mathbf{e}, \mathbf{h})$, and center $(\mathbf{c}, \mathbf{f}, \mathbf{i})$ of the billet under a liquid nitrogen flow rate of $80 \mathrm{~L} / \mathrm{min}(\mathbf{a}-\mathbf{c}), 160 \mathrm{~L} / \mathrm{min}(\mathbf{d}-\mathbf{f})$, and $240 \mathrm{~L} / \mathrm{min}(\mathbf{g}-\mathbf{i})$. 
The $2219 \mathrm{Al}$ alloy billets prepared by different liquid nitrogen flow rates were homogenized at $510{ }^{\circ} \mathrm{C}$ for $18 \mathrm{~h}$, and their second phases are shown in Figure 8. A large number of eutectic compounds exist in the grain boundaries under a liquid nitrogen flow rate of $80 \mathrm{~L} / \mathrm{min}$ and $240 \mathrm{~L} / \mathrm{min}$. These second phases are coarse, continuous, and netted, which cannot be completely eliminated by the heat treatment. When the liquid nitrogen flow rate is $160 \mathrm{~L} / \mathrm{min}$, more second phases are diffused into the $\alpha$-Al matrix and fewer second phases remain in the grain boundaries.
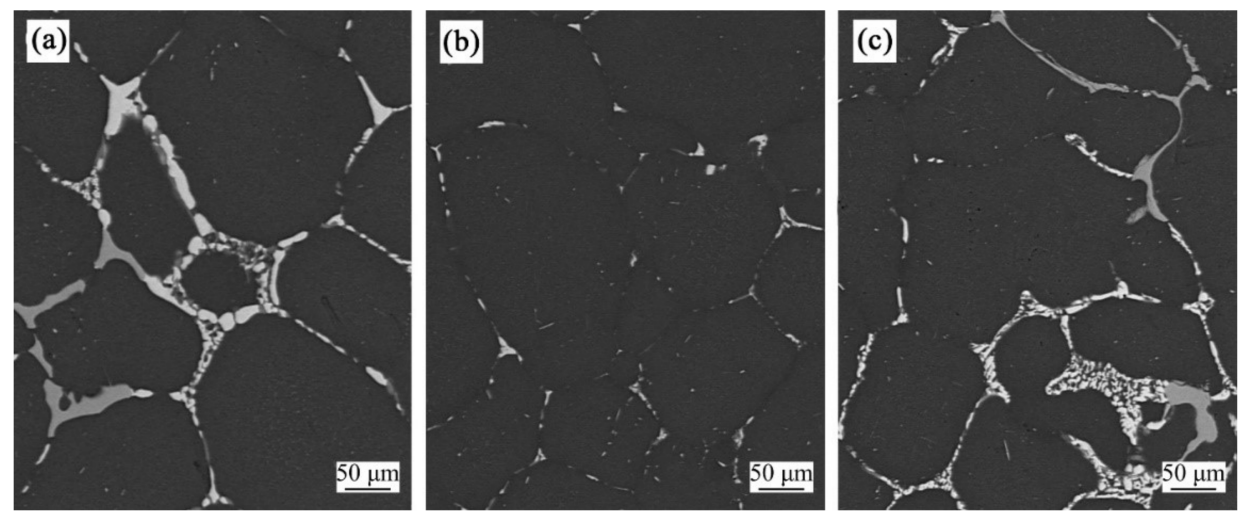

Figure 8. Second phases of the billet under a liquid nitrogen flow rate of $80 \mathrm{~L} / \mathrm{min}(\mathbf{a}), 160 \mathrm{~L} / \mathrm{min}(\mathbf{b})$, and $240 \mathrm{~L} / \mathrm{min}(\mathbf{c})$.

\subsection{Mechanical Properties}

The $2219 \mathrm{Al}$ alloys were solution treated at $535^{\circ} \mathrm{C}$ for $8 \mathrm{~h}$, quenched, and aging treated at $170{ }^{\circ} \mathrm{C}$ for $15 \mathrm{~h}$, successively. The mechanical properties were tested and are displayed in Table 1. It is obvious that the mechanical properties increase as the grain size decreases, which follows the Hall-Petch formula. Tensile strength, yield strength, and elongation are enhanced from 329-338 $\mathrm{MPa}, 237-246 \mathrm{MPa}$, and 4-5\% (liquid nitrogen flow rate of $80 \mathrm{~L} / \mathrm{min}$ ) to 373-379 MPa, 275-278 MPa, and 6-7\% (liquid nitrogen flow rate of $160 \mathrm{~L} / \mathrm{min}$ ). Because the homogeneity of the microstructure sharply decreases under a liquid nitrogen flow rate of $240 \mathrm{~L} / \mathrm{min}$, the ranges of tensile strength, yield strength, and elongation are enlarged to 287-394 MPa, 203-302 MPa, and 3-8\%, respectively.

Table 1. Mechanical properties in the different positions of the billet under different liquid nitrogen flow rates.

\begin{tabular}{|c|c|c|c|c|c|c|c|c|c|}
\hline Liquid Nitrogen Flow Rate & & $80 \mathrm{~L} / \mathrm{min}$ & & & $160 \mathrm{~L} / \mathrm{min}$ & & & $240 \mathrm{~L} / \mathrm{min}$ & \\
\hline Position & Edge & 1/2 Radius & Center & Edge & 1/2 Radius & Center & Edge & 1/2 Radius & Center \\
\hline Tensile strength (MPa) & 335 & 338 & 329 & 377 & 373 & 379 & 394 & 336 & 287 \\
\hline Yield strength $(\mathrm{MPa})$ & 246 & 244 & 237 & 275 & 276 & 278 & 302 & 241 & 203 \\
\hline Elongation (\%) & 4 & 5 & 4 & 7 & 6 & 6 & 8 & 5 & 3 \\
\hline
\end{tabular}

\section{Discussion}

The refinement of IEMS can be attributed to the coupled function of EMS and intercooling. The EMS is generated as a result of interactions between magnetic fields and alternating currents. Its effects upon microstructure formation mainly include two aspects. Firstly, the free dendrites collide mutually under the Lorentz force, and the secondary dendrite arms are broken to form new nuclei $[33,34]$. Hence, the number of nuclei increases. Secondly, the flow of melt along the circle of mold is promoted by the EMS, and the heat transfer among the whole melt is accelerated $[3,22]$. Hence, the temperature gradient between the edge and the center decreases. Meanwhile, more heat can be removed via intercooling and a graphite ring, which contributes to relatively lower levels of temperature field [21]. As a 
consequence, the grains' growth orientation is restrained, so more effective nuclei remain. Furthermore, the coarse columnar grains decrease and fine equiaxed grains increase.

When the intercooling liquid nitrogen flow rate is $80 \mathrm{~L} / \mathrm{min}$, the cooling intensity is small. Only the heat under and around the intercooling end can be removed. Therefore, the overall temperature of the melt is still high. The undercooling area is small and a few nuclei can be generated. However, some of them may flow into the superheated zone, resulting in a decrease in surviving nuclei $[35,36]$. As a result, the finally obtained microstructure is relatively coarse.

With the liquid nitrogen flow rates increasing to $160 \mathrm{~L} / \mathrm{min}$, the cooling effects enhance. The undercooling zone increases and more nuclei are generated. Meanwhile, the temperature field is relatively lower and more homogeneous, so more nuclei survive. Under the Lorentz force of IMES, the nuclei distribute more homogeneously in the sump. Moreover, the flow time of floating grains from the slurry zone to the sump bottom decreases because of the decrease in sump depth [37]. The growing time of those grains is restricted, which also promotes the refinement and inhomogeneity of microstructures.

When the intercooling liquid nitrogen flow rate reaches $240 \mathrm{~L} / \mathrm{min}$, some different characteristics appear in the microstructure. Firstly, the cooling intensity is further enhanced, meaning that more nuclei can be generated and transported with the melt flow into the edge of the billet. Therefore, it can be seen that the microstructure of the edge is much smaller than that of $160 \mathrm{~L} / \mathrm{min}$. Secondly, a large number of coarse dendrites exist in the $1 / 2$ radius and center of the billet, with an average grain size much larger and more inhomogeneous than that of the edge. This can be explained as follows: the slurry becomes wider from the edge to the center, which increases the settling time of floating grains [38]. Meanwhile, the temperature below and around the intercooling end decreases as the liquid nitrogen flow rate increases. Hence, the viscosity increases accordingly. The floating grains flow, settle, and completely solidify in the sump bottom, which allows enough time for the floating grains to grow [39]. Hence, coarse microstructures have formed, some of which were even larger than $1 \mathrm{~mm}$.

In the IMES DCC process, the $t_{1}, t_{2}, t_{3}$, and $t_{4}$ were measured and shown in Table 2. According to the formula (17), the heat transfer coefficients under a liquid nitrogen flow rate of $80 \mathrm{~L} / \mathrm{min}, 160 \mathrm{~L} / \mathrm{min}$, and $240 \mathrm{~L} / \mathrm{min}$ are $186 \mathrm{~W} /\left(\mathrm{m}^{2}{ }^{\circ} \mathrm{C}\right), 290 \mathrm{~W} /\left(\mathrm{m}^{2}{ }^{\circ} \mathrm{C}\right)$, and $387 \mathrm{~W} /\left(\mathrm{m}^{2}{ }^{\circ} \mathrm{C}\right)$, respectively. Meanwhile, the melt temperature where contacts with the intercooling end bottom were simulated and shown as follows: $624{ }^{\circ} \mathrm{C}$ for a heat transfer coefficient of $200 \mathrm{~W} /\left(\mathrm{m}^{2}{ }^{\circ} \mathrm{C}\right), 615{ }^{\circ} \mathrm{C}$ for a heat transfer coefficient of $300 \mathrm{~W} /\left(\mathrm{m}^{2}{ }^{\circ} \mathrm{C}\right)$, and $603{ }^{\circ} \mathrm{C}$ for a heat transfer coefficient of $400 \mathrm{~W} /\left(\mathrm{m}^{2}{ }^{\circ} \mathrm{C}\right)$. These temperatures can be considered as $t_{3}$, approximately. Table 3 shows the $t_{3}$ and heat transfer coefficient of experimental and simulated results. It can be inferred from the comparison that the experimental liquid nitrogen flow rate of $80 \mathrm{~L} / \mathrm{min}, 160 \mathrm{~L} / \mathrm{min}$, and $240 \mathrm{~L} / \mathrm{min}$ approximately correspond to the simulated heat transfer coefficient of $200 \mathrm{~W} /\left(\mathrm{m}^{2}{ }^{\circ} \mathrm{C}\right), 300 \mathrm{~W} /\left(\mathrm{m}^{2}{ }^{\circ} \mathrm{C}\right)$, and $400 \mathrm{~W} /\left(\mathrm{m}^{2}{ }^{\circ} \mathrm{C}\right)$, respectively.

Table 2. Experimental $t_{1}, t_{2}, t_{3}$, and $t_{4}$ under different liquid nitrogen flow rates.

\begin{tabular}{ccccc}
\hline Liquid Nitrogen Flow Rate (L/min) & $\mathbf{t}_{\mathbf{1}}\left({ }^{\circ} \mathbf{C}\right)$ & $\mathbf{t}_{\mathbf{2}}\left({ }^{\circ} \mathbf{C}\right)$ & $\mathbf{t}_{\mathbf{3}}\left({ }^{\circ} \mathbf{C}\right)$ & $\mathbf{t}_{\mathbf{4}}\left({ }^{\circ} \mathbf{C}\right)$ \\
\hline 80 & 208 & -105 & 617 & 442 \\
160 & 173 & -107 & 604 & 403 \\
240 & 154 & -108 & 595 & 384 \\
\hline
\end{tabular}


Table 3. Comparison of experimental and simulated results.

\begin{tabular}{ccccc}
\hline \multicolumn{3}{c}{ Experimental Results } & \multicolumn{3}{c}{ Simulated Results } \\
\hline $\begin{array}{c}\text { Liquid Nitrogen Flow Rate } \\
(\mathbf{L} / \text { min) }\end{array}$ & $\begin{array}{l}\mathbf{t}_{3} \\
\left({ }^{\circ} \mathbf{C}\right)\end{array}$ & $\begin{array}{c}\text { Heat Transfer Coefficient } \\
\left(\mathbf{W} /\left(\mathbf{m}^{2}{ }^{\circ} \mathbf{C}\right)\right)\end{array}$ & $\begin{array}{l}\mathbf{t}_{3} \\
\left({ }^{\circ} \mathbf{C}\right)\end{array}$ & $\begin{array}{c}\text { Heat Transfer Coefficient } \\
\left(\mathbf{W} /\left(\mathbf{m}^{2}{ }^{\circ} \mathbf{C}\right)\right)\end{array}$ \\
\hline 80 & 617 & 186 & 624 & 200 \\
160 & 604 & 290 & 615 & 300 \\
240 & 595 & 387 & 603 & 400 \\
\hline
\end{tabular}

\section{Conclusions}

The intercooling intensity is a primary parameter of IEMS DCC. Its effects on the temperature field and microstructure of large-scale $2219 \mathrm{Al}$ alloy billets have been investigated by simulation and experimentation, respectively. Furthermore, the formation of microstructures under different intercooling intensities has been discussed. The main conclusions are as follows:

(1) The intercooling intensity significantly affects the temperature distribution and sump depth. The affected area increases and the sump depth decreases as the intercooling heat transfer coefficient increases. The heat transfer coefficient should not exceed $500 \mathrm{~W} /\left(\mathrm{m}^{2}{ }^{\circ} \mathrm{C}\right)$ because the solid fraction of the intercooling end bottom may exceed $50 \%$.

(2) The average grain sizes in the edge, $1 / 2$ radius and center are $151 \pm 13 \mu \mathrm{m}, 159 \pm 14 \mu \mathrm{m}$, and $149 \pm 16 \mu \mathrm{m}$, respectively, under a liquid nitrogen flow rate of $160 \mathrm{~L} / \mathrm{min}$, which are much finer than that of $80 \mathrm{~L} / \mathrm{min}$ and more homogeneous than that of $240 \mathrm{~L} / \mathrm{min}$.

(3) The tensile strength, yield strength, and elongation under a liquid nitrogen flow rate of $160 \mathrm{~L} / \mathrm{min}$ are $373-379 \mathrm{MPa}, 275-278 \mathrm{MPa}$, and 6-7\%, which is higher than that of $80 \mathrm{~L} / \mathrm{min}$ and more homogeneous than that of $240 \mathrm{~L} / \mathrm{min}$.

(4) The relationship between experimental liquid nitrogen flow rates and simulated heat transfer coefficients has been determined. A liquid nitrogen flow rate of $80 \mathrm{~L} / \mathrm{min}$, $160 \mathrm{~L} / \mathrm{min}$, and $240 \mathrm{~L} / \mathrm{min}$ approximately correspond to the heat transfer coefficients of $200 \mathrm{~W} /\left(\mathrm{m}^{2}{ }^{\circ} \mathrm{C}\right), 300 \mathrm{~W} /\left(\mathrm{m}^{2}{ }^{\circ} \mathrm{C}\right)$, and $400 \mathrm{~W} /\left(\mathrm{m}^{2}{ }^{\circ} \mathrm{C}\right)$, respectively.

Author Contributions: Y.Q. designed the research, analyzed data, and wrote the paper; X.L. and M.L. helped to analyze the data and simulate the temperature field; N.Z. provided suggestions for model construction; K.Z. helped to obtain the funding support. All authors have read and agreed to the published version of the manuscript.

Funding: This work was supported by the Topmost Research Institution Construction Project of Guangdong Academy of Sciences (grant numbers 2021GDASYL-20210103107).

Institutional Review Board Statement: Not applicable.

Informed Consent Statement: Not applicable.

Data Availability Statement: Data sharing is not applicable to this article.

Conflicts of Interest: We declare that we have no conflict of interest.

\section{References}

1. Eskin, D.G. Physical Metallurgy of Direct Chill Casting of Aluminum Alloys; CRC Press: Boca Raton, FL, USA, 2008; pp. 9-12.

2. Zhou, L.; Luo, Y.J.; Zhang, Z.L.; He, M.; Xu, Y.N.; Zhao, Y.L.; Liu, S.; Dong, L.J.; Zhang, Z.F. Microstructures and macrosegregation of Al-Zn-Mg-Cu alloy billet prepared by uniform direct chill casting. Materials 2021, 14, 708-716. [CrossRef] [PubMed]

3. Qiu, Y.; Zhang, Z.F.; Luo, Y.J.; Gao, M.W.; Li, B.; Chen, C.S. Effect of coupled annular electromagnetic stirring and intercooling on the microstructures, macrosegregation and properties of large-sized 2219 aluminum alloy billets. Int. J. Mater. Res. 2018, 109, 469-475. [CrossRef]

4. Shi, C.; Wu, Y.J.; Mao, D.H.; Fan, G.F. Effect of ultrasonic bending vibration introduced by the L-shaped ultrasonic rod on solidification structure and segregation of sarge 2A14 ingots. Materials 2020, 13, 807-820. [CrossRef] [PubMed]

5. Wang, H.J.; Wang, C.; Mo, Y.; Wang, H.; Xu, J. Hot deformation and processing maps of Al-Zn-Mg-Cu alloy under couplingstirring casting. Mater. Res. Technol. 2018, 8, 1224-1234. [CrossRef] 
6. Venugopal, S.; Venugopal, P.; Mannan, S.L. Optimisation of cold and warm workability of commercially pure titanium using dynamic materials model (DMM) instability maps. J. Mater. Process. Technol. 2008, 202, 201-215. [CrossRef]

7. Wang, M.L.; Jin, P.P.; Wang, J.H.; Han, L. Hot deformation behavior of as-quenched 7005 aluminum alloy. Trans. Nonferrous Met. Soc. China 2014, 24, 2796-2804. [CrossRef]

8. Tiamiyu, A.A.; Badmos, A.Y.; Odeshi, A.G. Effects of temper condition on high strain-rate deformation of AA 2017 aluminum alloy in compression. Mater. Des. 2016, 89, 872-883. [CrossRef]

9. Mohanty, P.S.; Gruzleski, J.E. Mechanism of grain refinement in aluminium. Acta. Metall. Mater. 1995, 43, 2001-2012. [CrossRef]

10. Zou, H.; Pan, Q.L.; Shi, Y.J.; Chen, J.; Xiang, H.; Li, R.S.; Li, H. Effect of ultrasonic field on microstructure and mechanical properties of as-cast 7085 aluminum alloy. J. Cent. South Univ. 2018, 25, 1285-1294. [CrossRef]

11. Li, R.Q.; Liu, Z.L.; Chen, P.H.; Zhong, Z.T.; Li, X.Q. Investigation on the manufacture of a large-scale aluminum alloy ingot: Microstructure and Macrosegregation. Adv. Eng. Mater. 2017, 19, 1600375. [CrossRef]

12. Wang, F.Y.; Wang, X.J.; Cui, J.Z. Effect of low-frequency electromagnetic casting on micro-structure and macro-segregation of 5A90 alloy ingots. Materials 2020, 13, 2720-2733. [CrossRef] [PubMed]

13. Zuo, Y.B.; Cui, J.Z.; Dong, J.; Xu, F.X. Effects of low frequency electromagnetic field on the as-cast microstructures and mechanical properties of superhigh strength aluminum alloy. Mater. Sci. Eng. A 2005, 408, 176-181. [CrossRef]

14. Li, X.L.; Hu, S.; Wang, D.Y.; Qu, T.P.; Quan, Q.; Zhou, X.Z. Effect of electromagnetic frequency on the flow behavior in mold during bloom casting. Materials 2021, 11, 1828-1842. [CrossRef]

15. Wang, Y.F.; Zhao, S.D.; Guo, Y. Numerical simulation and experimental investigation of the preparation of aluminium alloy 2A50 semi-solid billet by electromagnetic stirring. Materials 2020, 13, 5470-5491. [CrossRef]

16. Guo, S.J.; Le, Q.C.; Zhao, Z.H.; Han, Y.; Cui, J.Z. Effect of a low frequency electromagnetic field on the direct-chill (DC) casting of AZ80 magnesium alloy ingots. Int. J. Mater. Res. 2006, 97, 1539-1544. [CrossRef]

17. Tang, M.O.; Xu, J.; Zhang, Z.F.; Bai, Y.L. 3D Numerical Simulation of Flow and Temperature Field in Semi-Solid Slurry Preparation by A-EMS. Mater. Sci. Forum. 2011, 689, 16-23. [CrossRef]

18. Zhang, Z.F.; Chen, X.R.; Xu, J.; Shi, L.K. Numerical simulation on electromagnetic field, flow field and temperature field in semisolid slurry preparation by A-EMS. Rare Met. 2010, 29, 635-641. [CrossRef]

19. Luo, Y.J.; Zhang, Z.F.; Gao, M.W.; Li, B.; Chen, C.S. Control of microstructure and macrosegregation of large-sized aluminium alloy billet by uniform direct chill casting. Int. J. Cast Met. Res. 2019, 32, 31-35. [CrossRef]

20. Luo, Y.J.; Zhang, Z.F.; Li, B.; Gao, M.W.; Qiu, Y.; He, M. Effects of annular electromagnetic stirring coupled with intercooling on grain refinement and homogeneity during direct chill casting of large-sized 7005 alloy billet. JOM 2017, 69, 2640-2643. [CrossRef]

21. Qiu, Y.; Zhang, Z.F. Effects of internal electromagnetic stirring on the microstructure refinement and composition homogenization of large-scale 7075 aluminum alloy billet. JOM 2021, 73, 3812-3818. [CrossRef]

22. Qiu, Y.; Zhang, Z.F.; Zhao, H.D. Internal electromagnetic stirring method for preparing a large-sized aluminum alloy billet. Int. J. Mater. Res. 2019, 110, 1083-1086. [CrossRef]

23. Qiu, Y.; Zhang, Z.F.; Zhao, H.D.; Xu, Y.T. Microstructure and macrosegregation of $\phi 508 \mathrm{~mm} 7050$ aluminum alloy billet under internal electromagnetic stirring. Mater. Sci. Forum 2020, 993, 130-137. [CrossRef]

24. Anderson-Wedge, K.; Avery, D.Z.; Daniewicz, S.R.; Sowards, J.W.; Allison, P.G.; Jordon, J.B.; Amaro, R.L. Characterization of the fatigue behavior of additive friction stir-deposition AA2219. Int. J. Fatigue 2021, 142, 105951-105960. [CrossRef]

25. Elangovan, K.; Balasubramanian, V. Influences of pin profile and rotational speed of the tool on the formation of friction stir processing zone in AA2219 aluminium alloy. Mater. Sci. Eng. A 2007, 459, 7-18. [CrossRef]

26. Lu, Y.L.; Wang, J.; Li, X.C.; Li, W.; Li, R.L. Zhou. D.S. Effects of pre-deformation on the microstructures and corrosion behavior of 2219 aluminum alloys. Mater. Sci. Eng. A 2018, 723, 204-211. [CrossRef]

27. Wang, H.M.; Yi, Y.P.; Huang, S.Q. Influence of pre-deformation and subsequent ageing on the hardening behavior and microstructure of 2219 aluminum alloy forgings. J. Alloys Compd. 2016, 685, 941-948. [CrossRef]

28. Hatić, V.; Mavrič, B.; Košnik, N.; Šarler, B. Simulation of direct chill casting under the influence of a low-frequency electromagnetic field. Appl. Math. Model. 2018, 54, 170-188. [CrossRef]

29. Bakhtiyarov, S.I.; Overfelt, R.A.; Meir, A.J.; Schmidt, P.G. Experimental measurements of velocity, potential, and temperature distributions in liquid aluminum during electromagnetic stirring. J. Appl. Mech. 2003, 70, 351-358. [CrossRef]

30. Caron, E.; Wells, M.A. Film boiling and water film ejection in the secondary cooling zone of the direct-chill casting process. Metall. Mater. Trans. B 2012, 43, 155-162. [CrossRef]

31. Weckman, D.C.; Niessen, P.A. A numerical simulation of the D.C. continuous casting process including nucleate boiling heat transfer. Metall. Mater. Trans. B 1982, 13, 593-602.

32. Luo, Y.J.; Zhang, Z.F. Numerical modeling of annular electromagnetic stirring with intercooling in direct chill casting of 7005 aluminum alloy billet. Prog. Nat. Sci. Mater. Int. 2019, 29, 81-87. [CrossRef]

33. Liotti, E.; Lui, A.; Vincent, R.; Kumar, S.; Guo, Z.; Connolley, Y.; Dolbnya, I.P.; Hart, M.; Arnberg, L.; Mathiesen, R.H.; et al. A synchrotron $\mathrm{X}$-ray radiography study of dendrite fragmentation induced by a pulsed electromagnetic field in an $\mathrm{Al}-15 \mathrm{Cu}$ alloy. Acta Mater. 2014, 70, 228-239. [CrossRef]

34. Flemings, M.C. Behavior of metal alloys in the semisolid state. Metall. Trans. B 1991, 22, 269-293. [CrossRef]

35. Guo, S.J.; Le, Q.C.; Zhao, Z.H.; Wang, Z.J.; Cui, J.Z. Microstructural refinement of DC cast AZ80 Mg billets by low frequency electromagnetic vibration. Mater. Sci. Eng. A 2005, 404, 323-329. [CrossRef] 
36. Zuo, Y.B.; Cui, J.Z.; Zhao, Z.H.; Zhang, H.T.; Li, L.; Zhu, Q.F. Mechanism of grain refinement of an Al-Zn-Mg-Cu alloy prepared by low-frequency electromagnetic casting. J. Mater. Sci. 2012, 47, 5501-5508. [CrossRef]

37. Nadella, R.; Eskin, D.G.; Du, Q.; Katgerman, K. Macrosegregation in direct-chill casting of aluminium alloys. Prog. Mater. Sci. 2008, 53, 421-480. [CrossRef]

38. Dong, Q.P.; Yin, Y.B.; Zhu, Z.; Nagaumi, H. Motion and distribution of floating grain in direct-chill casting of aluminum alloys: Experiments and numerical modeling. Materials 2020, 13, 5379-5393. [CrossRef] [PubMed]

39. Zhu, Q.F.; Zhao, Z.H.; Wang, X.J.; Cui, J.Z. Floating grains in the HDC casting 7075 aluminum alloy ingot. Appl. Mech. Mater. 2012, 117-119, 1531-1534. [CrossRef] 